\title{
CAMBRIDGE
}

\section{The Morphology of Chinese}

A Linguistic and Cognitive Approach

Jerome L. Packard

Jerome Packard analyses the linguistic and cognitive nature of Chinese words,

dispelling the common misconception that the Chinese language has no morphology.

$$
\text { £40.00 HB } 0521771129 \quad 352 p p
$$

\section{Tone Sandhi}

\section{Patterns across Chinese Dialects}

MatthewY. Chen

Matthew Chen's landmark study offers the most comprehensive analysis to date of the rich and complex patterns of tone used in Chinese languages. His book explores a range of important theoretical issues.

E50.00 HB $0521652723 \quad 574 p p$

\section{Radicalism and} Education Reform in 20th-Century China

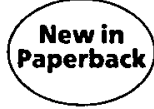

The Search for an Ideal Development Model Suzanne Pepper

This is the first comprehensive book to cover the whole sweep of twentieth-century Chinese education at a high standard of scholarship.

$\begin{array}{llll}\mathbf{E 5 0 . 0 0} & \text { HB } & 0521496691 & 622 \mathrm{pp} \\ \mathbf{E 1 6 . 9 5} & \text { PB } & 0521778603 & \end{array}$

Stanford University Press books are distributed by Cambridge University Press

Cambridge books are available from good bookshops. Alternatively you may order direct using your credit card. Phone UK $+44(0) 1223326050$, fax UK +44 (0)1223326111, or e-mail directcustserve@cup.cam.ac.uk
Manslaughter, Markets, and Moral Economy in China

Violent Disputes over Property Rights in 18th-Century China

Thomas Buoye

Thomas Buoye examines the impact of large-scale economic change on social conflict in eighteenth-century China. He draws upon a large body of documented violent property disputes to recreate the social tensions fostered by the growth of property rights in land, a population explosion, and the increasing strain on land and resources.

€37.50 HB $0521640458 \quad 288 p p$

\section{Factionalism in Chinese Communist Politics}

Jing Huang

In this book, Jing Huang examines the role of factionalism in leadership relations and policy making. His detailed knowledge of intra-Party politics offers a new understanding of still-disputed struggles behind the high walls of leadership in Zhongnanhai.

E40.00 HB $0521622840 \quad 478 \mathrm{pp}$

Cadres and Corruption

The Organizational Involution of the Chinese Communist Party

Xiaobo Lü

'... this book examines the changing patterns of official corruption from an entirely new perspective. Thoroughly researched, tightly argued, and succinctly written, it offers an excellent bird's-eye view of a major problem.'

Hong Yung Lee, University of California, Berkeley

E35.00 HB $\quad 0804739587 \quad 388 \mathrm{pp}$ 


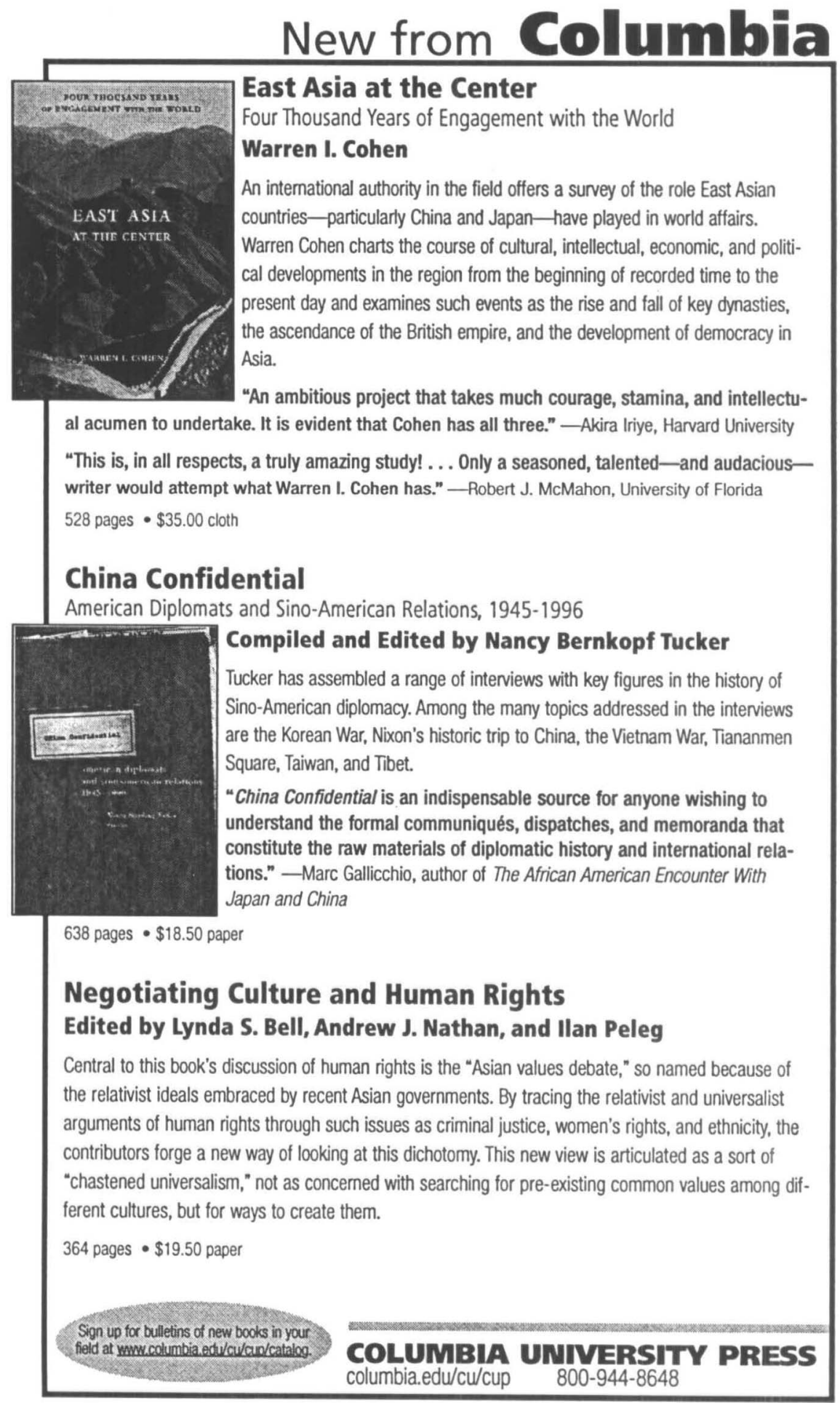




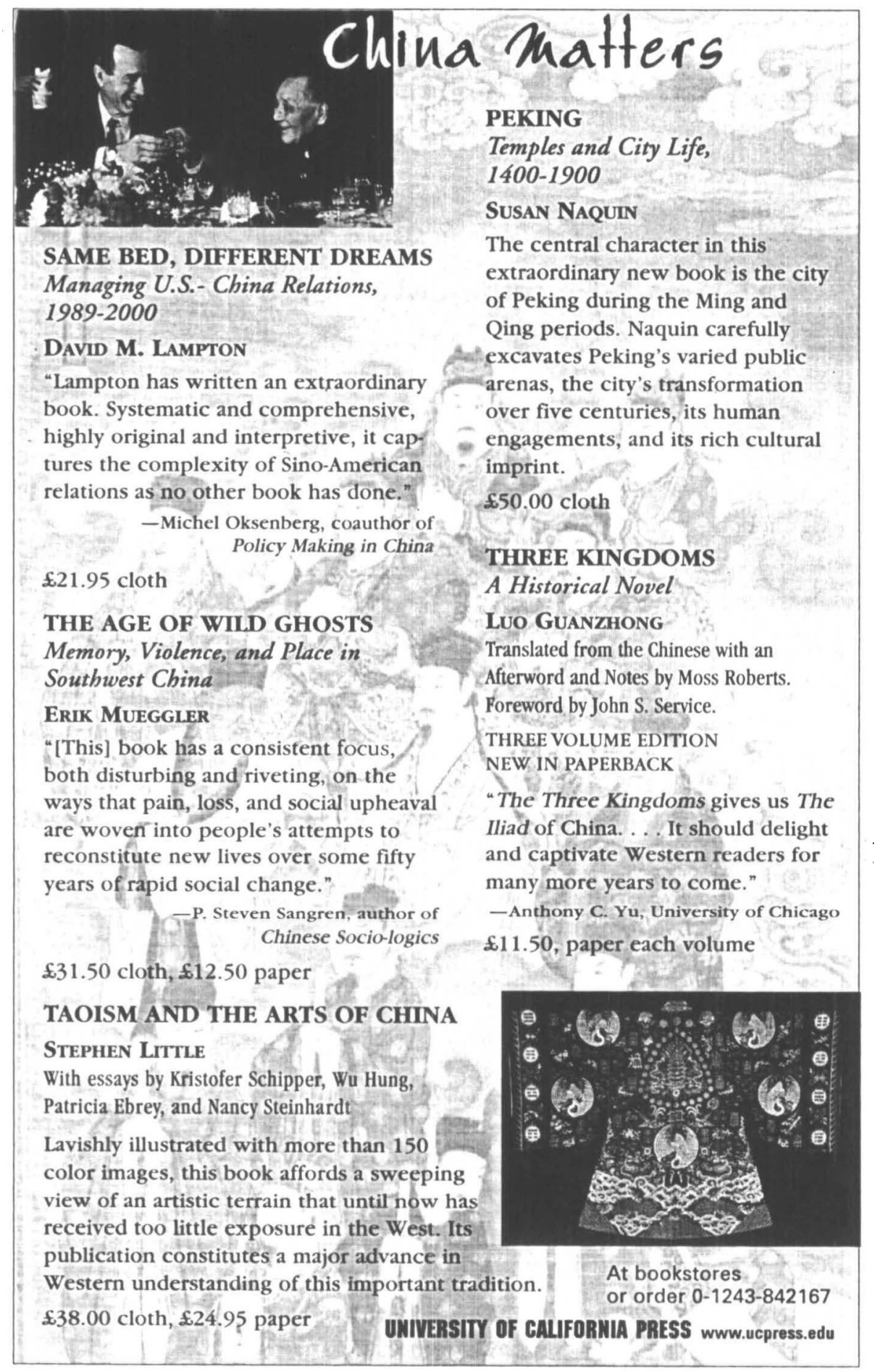




\section{CHINESE STUDIES FROM HARVARD}

\section{THE ENCYCLOPEDIA OF THE CHINESE OVERSEAS EDITED BY LYNN PAN}

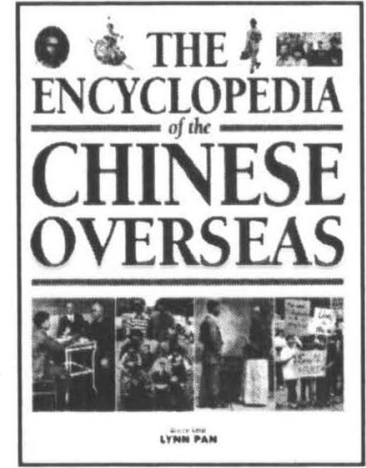

(2) THE \& ENCYCLOPEDIA CHINESE OVERSEAS

"A valuable and-particularly for an encyclopedia-very readable work. Its unique strength is that half of it is made up of very substantial narrative, descriptive, and analytical chapters of different facets of the lives of Chinese overseas. The editor has succeeded remarkably in combining high standards of scholarship with an extremely readable style of exposition."

-Prasenjit Duara, University of Chicago $\$ 59.95$ cloth

\section{THE GENERALISSIMO'S SON Chiang Ching-kuo and the Revolutions in China and Taiwan JAY TAYLOR}

By reacting to changing economic, social, and political dynamics on Taiwan, Deng Xiaoping's sweeping reforms on the mainland, and other international events, Chiang Ching-kuo, son of Generalissimo Chiang Kai-shek, led Taiwan on a zigzag but ultimately successful transition from dictatorship to democracy. Jay Taylor underscores the interaction of political developments on the mainland and in Taiwan and concludes that if China ever makes a similar transition, it will owe much to the Taiwan example and the Generalissimo's son.

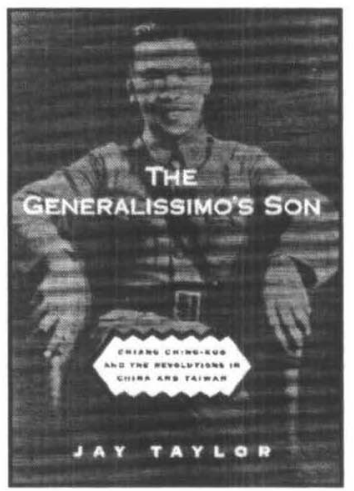
$\$ 39.95$ cloth

H A R V A R D U U N I V E R S I T Y P R E S S 8004482242 . WW W. HUP. HARVARD. EDU 


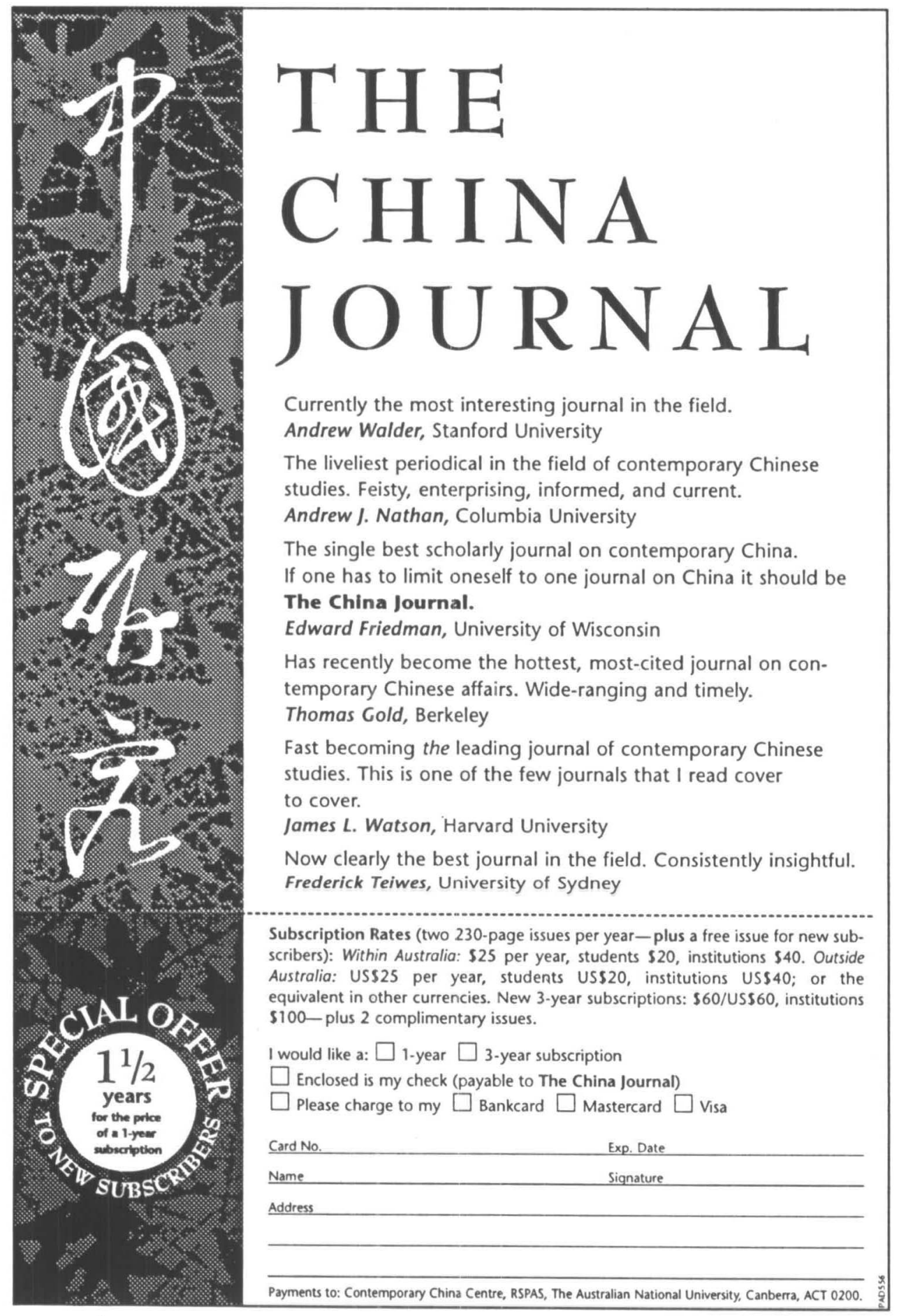




\section{New Views of China}

\section{CHALLENGING THE} MANDATE OF HEAVEN

Social Protest and State Power in China

Elizabeth J. Perry

352 pages 0-7656-0444-2 Cloth $\$ 69.95$

CHINA AND CHRISTIANITY

Burdened Past, Hopeful Future

Stephen Uhalley, Jr. and

Wu Xiaoxin, Eds.

497 pages $0-7656-0661-5$ Cloth $\$ 79.95$

\section{CHINA'S RETREAT FROM EQUALITY}

Income Distribution and

Economic Transition

Carl Riskin, Zhao Renwei and

Li Shi, Eds.

388 pages $\quad 0-7656-0690-9$ Cloth $\$ 85.00$ 0691-7 Paper $\$ 32.50$

\section{CHINA'S WORKERS}

UNDER ASSAULT

The Exploitation of Labor in a

Globalizing Economy

Anita Chan

232 Pages 0-7656-0357-8 Cloth $\$ 58.95$ 0358-6 Paper $\$ 22.95$

\section{CHINESE POLITICAL}

\section{CULTURE}

Hua Shiping

352 pages $0-7656-0565-1$ Cloth \$68.95

\section{ELITE POLITICS IN}

\section{CONTEMPORARY CHINA}

Joseph Fewsmith

232 pages 0-7656-0686-0 Cloth $\$ 50.95$

0687-9 Paper $\$ 21.95$

\section{EYEWITNESSES TO \\ MASSACRE}

American Missionaries Bear Witness to Japanese Atrocities in Nanjing

Zhang Kaiyuan, Ed.

Foreword by Donald MacInnis

320 pages $0-7656-0684-4$ Cloth $\$ 45,00$

\section{PEASANTS WITHOUT}

\section{THE PARTY}

Grass-roots Movements in

Twentieth Century China

Lucien Bianco

300 pages 1-56324-839-5 Cloth $\$ 64.95$ 840-9 Paper $\$ 26.95$

\section{SOLDIERS OF FORTUNE}

The Rise and Fall of the Chinese Military-Business Complex, 1978-1998

James Charles Mulvenon

320 pages $\quad 0-7656-0579-1$ Cloth \$69.95 0580-5 Paper $\$ 27.95$

Featuring a translation of Bus Stop by Gao Xingjian, Winner of the 2000 Nobel Prize for Literature

\section{THEATER AND} SOCIETY An Anthology of Contemporary Chinese Drama Haiping Yan, Ed.

376 pages 0-7656-0307-1 Cloth $\$ 62.95$ 0308-X Paper $\$ 24.95$ 
Published by Oxford University Press on behalf of the School of Oriental and African Studies, University of London 